\title{
Toxicity of Carnoy's solution toward human keratinocytes: an in vitro study
}

\section{Aécio Abner Campos PINTO JÚNIOR ${ }^{(a)}$}

Karolina Skarlet Silva VIANA(b)

Lucas Guimarães ABREU(c) (ID

Clésia Cristina NASCENTES(d)

Ivana Márcia Alves DINIZ(e)

Ricardo Alves MESQUITA ${ }^{(f)}$

Vanessa Fátima BERNARDES ${ }^{(b)}$ (iD

(a) Centro Universitário de Belo Horizonte

- Uni-BH, College of Dentistry, Belo

Horizonte, MG, Brazil.

(b) Universidade Federal de Minas Gerais - UFMG, Biological Sciences Institute, Department of Pathology, Belo Horizonte, MG, Brazil.

(c) Universidade Federal de Minas Gerais UFMG, School of Dentistry, Department of Child's and Adolescent's Oral Health, Belo Horizonte, MG, Brazil.

(d) Universidade Federal de Minas Gerais UFMG, Institute of Mathematical Sciences, Department of Chemistry, Belo Horizonte, MG, Brazil.

(e) Universidade Federal de Minas Gerais UFMG, School of Dentistry, Department of Restorative Dentistry, Belo Horizonte, MG, Brazil.

(f) Universidade Federal de Minas Gerais UFMG, School of Dentistry, Department of Oral Surgery and Pathology, Belo Horizonte, MG, Brazil.

Declaration of Interests: The authors certify that they have no commercial or associative interest that represents a conflict of interest in connection with the manuscript.

\section{Corresponding Author:}

Vanessa Fátima Bernardes

E-mail: bernardesvf@icb.ufmg.br

ht1ps://doi.org/10.1590/1807-3107bor-2021.vol35.0124

Submitted: August 26, 2020

Accepted for publication: May 3, 2021

Last revision: May 20, 2021
Abstract: The present study aimed to characterize the chemical elements and cytotoxicity of Carnoy's solution (CS) by comparing two different trademarked products (one Brazilian [NCS] and another imported [ICS]) using inductively coupled plasma mass spectrometry (ICP-MS) and human keratinocyte (HaCaT) cultures. For performing ICP-MS, the solutions were diluted according to calibration curves, and the chemical elements were analyzed with a spectrometer. HaCaT cells were exposed to CS concentrations ranging from $0.10 \%$ to $20 \%$ for 3 or 5 min. Cell viability was evaluated immediately (T0), $24 \mathrm{~h}$ (T1), and 7 days (T2) after exposure to CS using 3-(4,5-dimethylthiazol-2-yl)-2, 5-diphenyl-tetrazolium bromide (MTT) reduction assay. Data were analyzed using a $t$-test for ICP-MS and analysis of variance followed by Tukey's post-hoc test for MTT assay, both considering statistical significance at $\mathrm{p}<0.05$. ICP-MS results revealed that ICS presented significantly lower concentrations of 12 chemical elements than NCS. The results of MTT assay revealed that at T0, ICS was more cytotoxic than NCS regardless of the time of exposure $(p<0.05)$. At T1, the only difference between the groups was at a concentration of $0.10 \%$ after 5 min of exposure. At T2, at a concentration of $0.5 \%$, ICS resulted in a significant reduction in cell viability compared to NCS $(p<0.05)$. Thus, the results showed that ICS was more cytotoxic than NCS. Collectively, our findings suggest that the individual compositions of different CS formulations should be investigated.

Keywords: HaCaT Cells; Mass Spectrometry; Odontogenic Cysts.

\section{Introduction}

The formulation of Carnoy's solution (CS) was first described by Zollinger and Moritz in 1932 as a necrobiotic agent to treat cystic lesions in dog brains. ${ }^{1}$ However, an important neurotoxic characteristic of the drug was observed when saphenous rat nerves were exposed to different substances commonly used in oral and maxillofacial surgery. It was shown that exposure to CS may cause persistent neural function deficits, depending on the duration of exposure. ${ }^{2}$ This adverse effect was further demonstrated in a rabbit model, in which considerable damage to axonal contents of the inferior alveolar nerve was observed upon contact with CS for periods longer than $3 \mathrm{~min}^{3}$ 
Despite being recognized as toxic, CS has been established as an adjuvant tool in surgical procedures to excise odontogenic keratocysts (OKCs), due to the reduced risk of recurrence of these lesions when the drug is used. ${ }^{4,5}$ Voorsmit et al. ${ }^{5}$ demonstrated that CS penetrates different types of tissues, including the cell walls of OKCs. This is of particular importance because OKCs have marked potential for recurrence in cases where fragments of the cyst epithelium remain after surgical procedures with incomplete lesion removal. ${ }^{5,6,7}$ Moreover, CS promotes tissue fixation, thus minimizing the risk of epithelial cell survival and subsequent lesion regrowth. ${ }^{8,9}$ Furthermore, the use of ferric chloride to cauterize tissues promotes the elimination of these cells. ${ }^{5,6}$ Since the application of CS to lesions was first proposed, several studies have demonstrated treatment strategies aimed at reducing the recurrence rates of cysts. ${ }^{6,10-21}$ Despite its broad clinical application, some unanswered questions regarding individual CS formulations remain. In Brazil, both local and imported trademarked CS preparations are available. The original formulation of CS comprises absolute ethanol (60\%), chloroform $(30 \%)$, glacial acetic acid (10\%), and ferric chloride $(0.1 \mathrm{mg} / \mathrm{mL}){ }^{22}$ However, when concerns about the carcinogenic properties of chloroform emerged, the US Food and Drug Administration (FDA) prohibited its inclusion in CS. ${ }^{23}$ Subsequently, a modified CS formulation was tested, albeit without success, as a significantly higher recurrence rate of OKCs was observed compared to the original CS formulation. ${ }^{24}$ Thus, the current CS formulation still contains chloroform. Studies are yet to address the ideal time of tissue exposure to CS. A previous study advocated that CS should be used for $5 \mathrm{~min},{ }^{5}$ while others have reported that a period of $3 \mathrm{~min}$ should be used. ${ }^{3,11}$ Considering that in vitro analysis of the cellular effects of CS may elucidate some of these queries, the aim of the present study was to assess CS cytotoxicity by comparing two different trademarked formulations and periods of exposure to the drug on human keratinocyte (HaCaT) cultures. In addition, the chemical elements present in both CS formulations were qualitatively and quantitatively analyzed. Our data indicate that the CS formulation may influence the viability of epithelial cells.

\section{Methodology}

\section{Reagents and chemicals}

Two different trademarked formulations of CS were tested. One solution, national Carnoy's solution (NCS; group 1) was obtained from Synth ${ }^{\circledR}$ Laboratory (Synth, Diadema, Brazil), while the other, imported Carnoy's solution (ICS; group 2), was procured from Merck ${ }^{\circledR}$ Laboratory (Merck, Darmstadt, Germany). The composition of CS in both the groups was the same, as described by Cuttler and Zollinger (1933), as follows: absolute ethanol (60\%), chloroform (30\%), glacial acetic acid $(10 \%)$, and ferric chloride $(0.1 \mathrm{mg} / \mathrm{mL}){ }^{22}$

\section{Inductively coupled plasma mass spectrometry (ICP-MS)}

The chemical elements present in both CSs were determined by ICP-MS using the standard addition method. All analyses were performed using an Agilent 7700 ICP-MS/MS spectrometer (Agilent Technologies, Santa Clara, USA). The argon gas used was of $99.998 \%$ purity (Air Products, Allentown, USA). To avoid polyatomic interferences, helium gas with a flow rate of $4.7 \mathrm{~mL} / \mathrm{min}$ was used. All solutions were prepared using distilled-deionized water (resistivity $>18.2 \mathrm{M} \Omega \mathrm{cm}$ ) obtained from a Milli-Q system (Millipore, Bedford, USA). The standard calibration curves were prepared from 0 to $50 \mu \mathrm{g} / \mathrm{L}$, and the dilution factor for the sample was 10 . The ICP-MS/MS operating conditions and mass-to-charge ratios $(m / z)$ are listed in Table 1.

\section{Cell culture}

A commercially available human immortalized epithelial cell line (HaCaT cells) was thawed and cultured in Dulbecco's modified essential medium (DMEM). It was supplemented with $10 \%$ fetal bovine serum (Gibco/Invitrogen, Grand Island, USA), 1\% penicillin, $1 \%$ streptomycin, and $0.2 \%$ fungizone and incubated in a $95 \%$ humidified atmosphere containing $5 \% \mathrm{CO}_{2}$ at $37^{\circ} \mathrm{C}$. Cells were seeded at a density of $1 \times 10^{4}$ cells/well onto 96-well microplates in quadruplicate.

To evaluate the effect of the CSs on HaCaT cells, serial dilutions of the solutions were prepared 
Table 1. Operating conditions for the Agilent 7700 ICP-MS/MS.

\begin{tabular}{lc}
\hline Instrument parameter & Operating condition \\
\hline $\mathrm{RF}$ applied power $(\mathrm{kW})$ & 1.50 \\
Plasma gas flow rate $(\mathrm{L} \mathrm{min}-1)$ & 12.0 \\
Carrier gas flow rate $(\mathrm{L} \mathrm{min}-1)$ & 1.0 \\
Auxiliary gas flow rate $\left(\mathrm{L} \mathrm{min}^{-1}\right)$ & 1.8 \\
Nebulizer & Micromist \\
Spray chamber & $\mathrm{Scott}$ type - double pass \\
lsotopes & ${ }^{24} \mathrm{Mg}^{27} \mathrm{Al},{ }^{44} \mathrm{Ca},{ }^{51} \mathrm{~V},{ }^{52} \mathrm{Cr}^{55} \mathrm{Mn},{ }^{59} \mathrm{Co},{ }^{60} \mathrm{Ni}{ }^{63} \mathrm{Cu},{ }^{66} \mathrm{Zn},{ }^{75} \mathrm{As},{ }^{88} \mathrm{Sr},{ }^{107} \mathrm{Ag},{ }^{137} \mathrm{Ba},{ }^{206} \mathrm{~Pb},{ }^{209} \mathrm{Bi}$ \\
\hline
\end{tabular}

using phosphate-buffered saline (PBS). First, a preliminary study was conducted to determine the CS concentration that results in 50\% cytotoxicity. Accordingly, CS at concentrations of $90 \%, 80 \%, 70 \%$, $60 \%, 50 \%, 40 \%, 30 \%, 20 \%, 10 \%, 1 \%$, and $0.10 \%$ were evaluated immediately after the exposure of cell cultures to the solution. These initial tests allowed us to verify that concentrations greater than $20 \%$ damaged the microplate, rendering the analysis in the spectrophotometer unfeasible. Accordingly, CSs were further tested at lower concentrations $(10 \%$, $1 \%, 0.75 \%, 0.5 \%, 0.25 \%$, and $0.10 \%$ ) for each group and tested immediately (T0), $24 \mathrm{~h}$ (T1), and 7 days (T2) after the exposure of cell cultures to both CS groups. At all time periods, cells were exposed for 3 or 5 min to each group of CS to evaluate whether the time of exposure was important for cell survival. After exposure to CSs, cell cultures were washed once with PBS, and fresh culture medium was added. A control group of cells (untreated cells) cultured under ideal conditions was used for comparison. Cell viability was assessed using the 4,5-dimethylthiazol2-yl)-diphenyltetrazolium bromide microculture tetrazolium (MTT) assay (Invitrogen/Vybrant MTT, Molecular Probes, Eugene, USA), according to the manufacturer's instructions. Briefly, $10 \mu \mathrm{L}$ of MTT and $90 \mu \mathrm{L}$ of fresh DMEM were added to the cells for $3 \mathrm{~h}$. Next, formazan crystals were diluted using $50 \mu \mathrm{L} /$ well of dimethyl sulfoxide. The optical density was measured at $540 \mathrm{~nm}$ using a microplate reader (Norgen $^{\mathrm{TM}}$, BioTek Corporation, Ontario, Canada). For data analysis, the optical density value corresponding to untreated cells was considered $100 \%$. Cell survival was calculated as the percentage of dye accumulated in the experimental groups compared with untreated cells.

\section{Statistical Analysis}

Cell viability determined by MTT assay was evaluated according to the classification system described in previous studies. ${ }^{25,26}$ Statistical analysis was performed using the Statistical Package for the Social Sciences (SPSS), version 20.0, for Windows (SPSS, Inc., Armonk, USA). Data from the MTT assay were analyzed using one-way analysis of variance, followed by Tukey's post-hoc test. For the evaluation of ICP-MS results, a $t$-test for dependent and non-matched samples was conducted to compare both groups. The level of significance was set at $\mathrm{p}<0.05$.

\section{Results}

\section{ICP-MS}

The ICP-MS analysis detected 16 and 15 chemical elements in NCS and ICS, respectively. Both CS formulations contained $\mathrm{Bi}, \mathrm{Pb}, \mathrm{Ba}, \mathrm{Sr}, \mathrm{As}, \mathrm{Zn}, \mathrm{Cu}, \mathrm{Ni}, \mathrm{Co}$, $\mathrm{Mn}, \mathrm{Cr}, \mathrm{V}, \mathrm{Ca}, \mathrm{Al}$, and $\mathrm{Mg}$, with NCS also containing $\mathrm{Ag}$, which was under the limit of detection (LD) in ICS. Differences between NCS and ICS were statistically significant for 12 elements, and in general, increased concentrations of the chemical elements were observed in NCS. In contrast, reduced concentrations of Zn, V, and Ca were observed in ICS compared with NCS. Among Zn, V, and Ca, only V showed a significant difference between the groups (Table 2).

\section{MTT Assay}

Figure 1 depicts the results of the MTT assay immediately after (T0) the exposure of cell cultures to the CSs diluted up to a concentration of $20 \%$ (preliminary study). The concentration of $0.10 \%$ presented cytotoxicities ranging between $40 \%$ and $60 \%$ for both groups of CS. Cells exposed to NCS showed 
Toxicity of Carnoy's solution toward human keratinocytes: an in vitro study

Table 2. ICP-MS results for both national and imported Carnoy's solutions.

\begin{tabular}{|c|c|c|c|c|c|}
\hline \multirow{2}{*}{ Chemical elements } & \multicolumn{2}{|c|}{ National Carnoy's solution (SYNTH $\left.{ }^{\circledR}\right)$} & \multicolumn{2}{|c|}{ Imported Carnoy's solution (MERCK $\left.{ }^{\circledR}\right)$} & \multirow{2}{*}{$\mathrm{p}$-value } \\
\hline & Mean $(\mu \mathrm{g} / \mathrm{L})$ & $\mathrm{SD}(\mu \mathrm{g} / \mathrm{L})$ & Mean $(\mu \mathrm{g} / \mathrm{L})$ & $\mathrm{SD}(\mu \mathrm{g} / \mathrm{L})$ & \\
\hline Bi (Bismuth) & 3281 & 31 & 323.5 & 67.1 & $<0.001$ \\
\hline $\mathrm{Pb}$ (Lead) & 10.08 & 2.10 & 1.47 & 0.12 & 0.017 \\
\hline Ba (Barium) & 20.58 & 0.58 & 7.62 & 0.68 & $<0.001$ \\
\hline Ag (Silver) & 9.07 & 1.03 & $<\mathrm{LD}$ & - & 0.004 \\
\hline Sr (Strontium) & 11.88 & 1.05 & 10.30 & 0.66 & 0.020 \\
\hline As (Arsenic) & 2.59 & 0.57 & 1.88 & 0.17 & 0.092 \\
\hline Zn (Zinc) & 158.5 & 5.9 & 158.6 & 12.1 & 0.980 \\
\hline Cu (Copper) & 42.01 & 2.24 & 21.81 & 6.86 & 0.017 \\
\hline $\mathrm{Ni}$ (Nickel) & 224.7 & 27.6 & 122.3 & 6.2 & 0.014 \\
\hline Co (Cobalt) & 91.06 & 0.76 & 22.27 & 2.82 & $<0.001$ \\
\hline Mn (Manganese) & 246.3 & 10.7 & 51.69 & 3.86 & $<0.001$ \\
\hline $\mathrm{Cr}$ (Chromium) & 426.6 & 28.5 & 285.9 & 35.0 & 0.001 \\
\hline V (Vanadium) & 14.66 & 2.03 & 20.68 & 3.76 & 0.026 \\
\hline $\mathrm{Ca}$ (Calcium) & 779.6 & 14.3 & 1008 & 120 & 0.065 \\
\hline Al (Aluminum) & 388.4 & 27.5 & 217.4 & 12.4 & 0.003 \\
\hline Mg (Magnesium) & 411.3 & 1.3 & 394.8 & 7.6 & 0.045 \\
\hline
\end{tabular}

significantly higher viability than those exposed to ICS regardless of the time of exposure ( 3 or 5 min; $\mathrm{p}<0.05)$. Concentrations higher than $0.10 \%$ were highly cytotoxic to the oral keratinocytes, presenting with more than $90 \%$ cell death, irrespective of the CS group used and the duration of exposure ( 3 or $5 \mathrm{~min}$ ).

After the preliminary study, concentrations ranging between $0.10 \%$ (around $50 \%$ cytotoxicity) and
$10 \%$ (minor concentration with the highest cytotoxicity) were tested to detect differences between both groups of CS and periods of exposure over prolonged time intervals. After $24 \mathrm{~h}$ (T1) of exposure of the cell cultures to the CSs, a dose-dependent response curve for both formulations, irrespective of the period of contact, was constructed (Figure 2). At this time interval, the only statistical difference between the groups was at

Oh

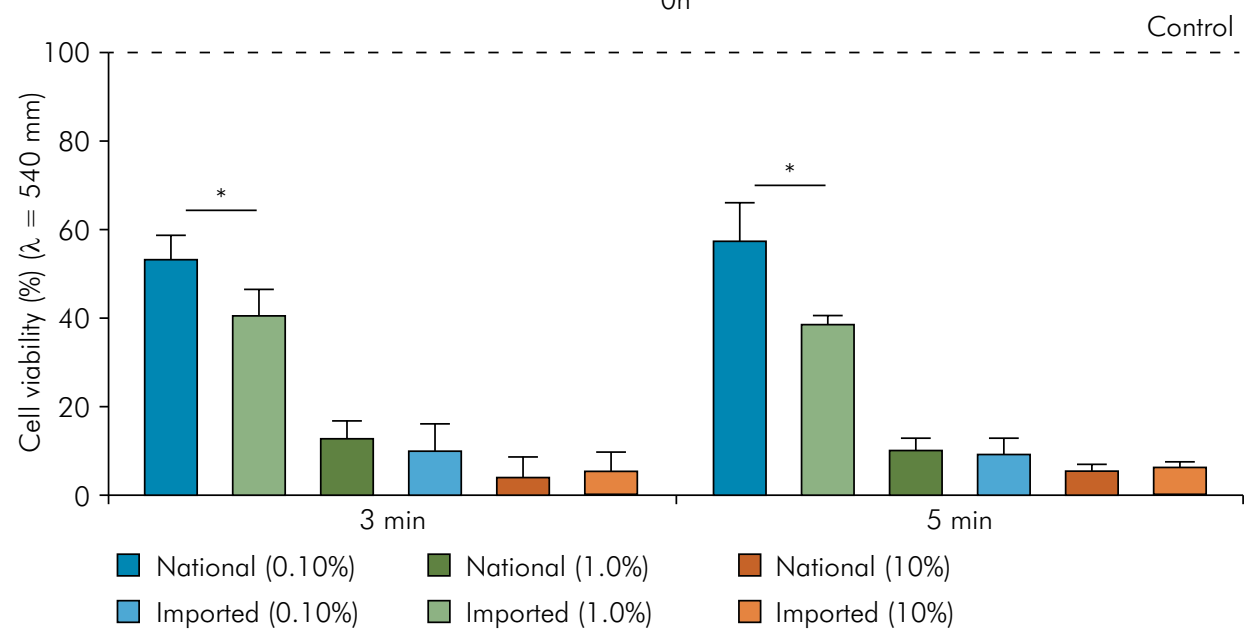

Figure 1. MTT assay immediately (TO) after exposure of cell cultures to the different CSs diluted up to a concentration of $10 \%$, comparing both NCS and ICS. 
a concentration of $0.10 \%$ and exposure time of $5 \mathrm{~min}$ $(\mathrm{p}<0.05)$, where the cells exposed to NCS presented higher viability than those exposed to ICS.

The data obtained for the MTT assay after 7 days (T2) are shown in Figure 3. Cell cultures treated with both CSs at concentrations of $0.10 \%$ and $0.25 \%$ subsequently survived and proliferated. At a concentration of $0.5 \%$, cells exposed to ICS presented a significant reduction in viability compared with NCS regardless of the period of exposure $(\mathrm{p}<0.05)$. At concentrations greater than
$0.5 \%$, a significant number of cells exposed to both CSs died, with no recovery of their viability after 7 days (T2) of culture (Figure 3).

Regarding the exposure time to CS (Figure 4), considering each CS, the time of 3 or 5 min was irrelevant for cell growth in most analyses. The only significant difference was found at the concentration of $0.50 \%$ for ICS and $0.75 \%$ for both ICS and NCS, wherein cell viability was significantly increased after 5 min (Figure 4c).

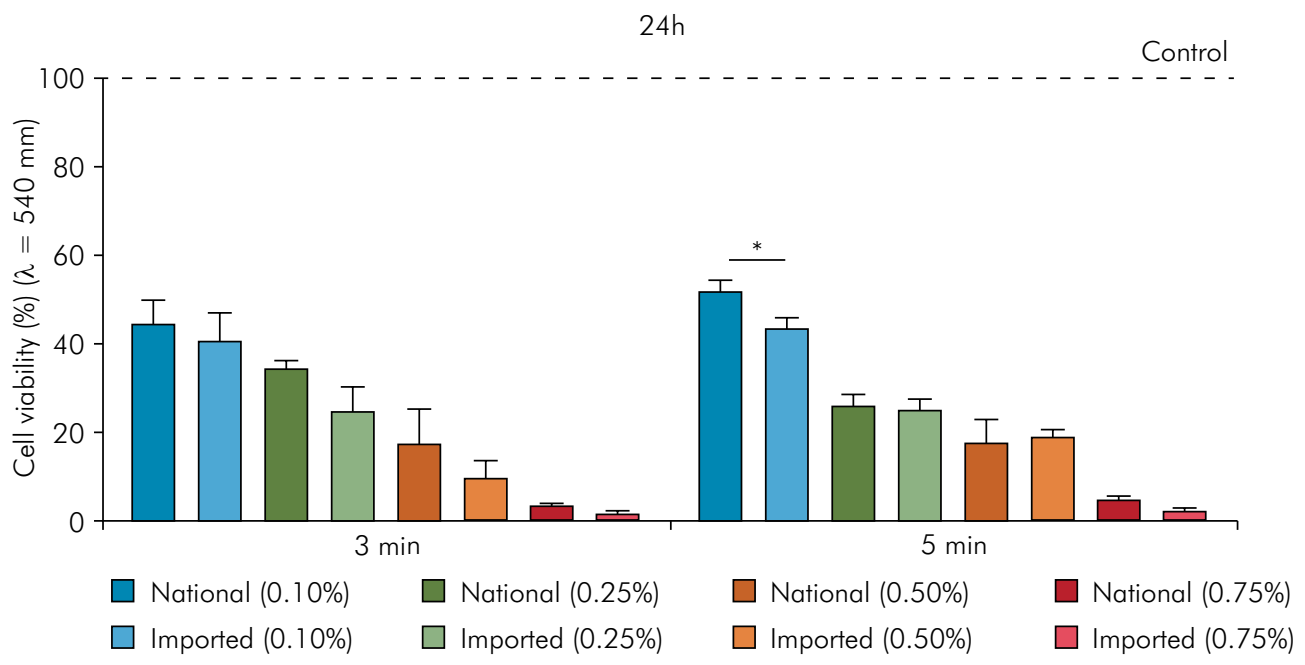

Figure 2. MTT assay $24 \mathrm{~h} \mathrm{(T1)} \mathrm{after} \mathrm{exposure} \mathrm{of} \mathrm{cell} \mathrm{cultures} \mathrm{to} \mathrm{the} \mathrm{different} \mathrm{CSs} \mathrm{diluted} \mathrm{to} \mathrm{concentrations} \mathrm{ranging} \mathrm{from} 0.10 \%$ to $0.75 \%$; comparison of epithelial cells exposed to both NCS and ICS for 3 or 5 min. \# indicates statistical difference between the control and test groups.

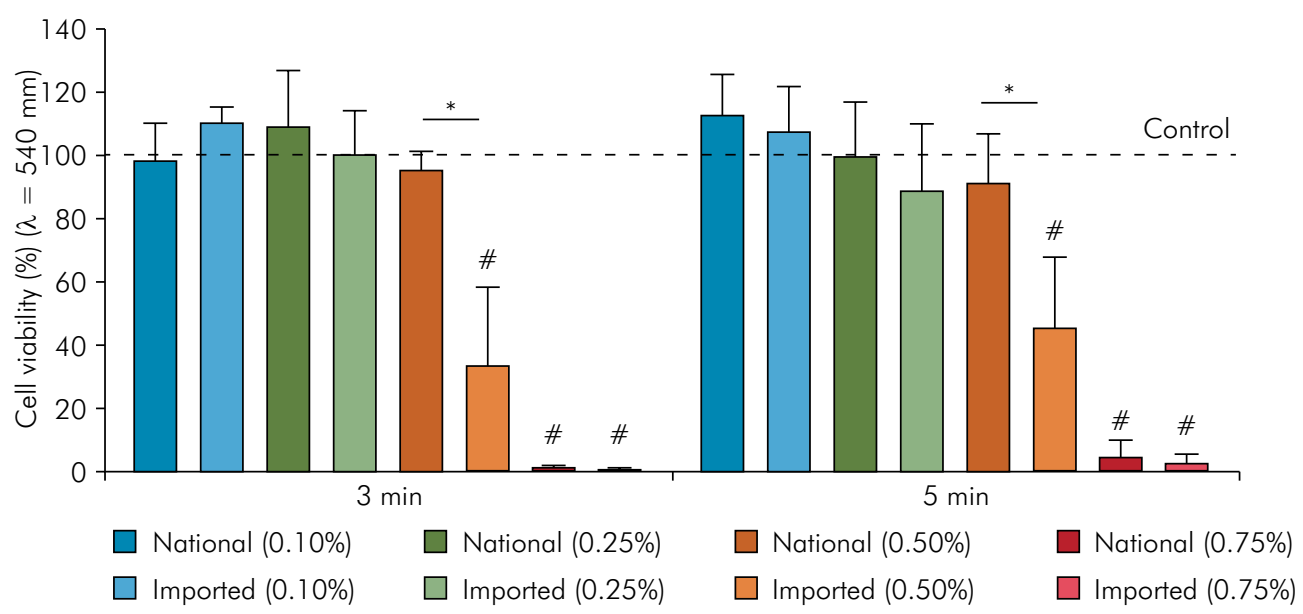

Figure 3. MTT assay 7 days (T2) after the exposure of cell cultures to the different CSs diluted to concentrations ranging from $0.10 \%$ to $0.75 \%$; comparison of epithelial cells exposed to NCS and ICS for 3 or $5 \mathrm{~min}$. \# indicates statistical difference between the control and test groups. 

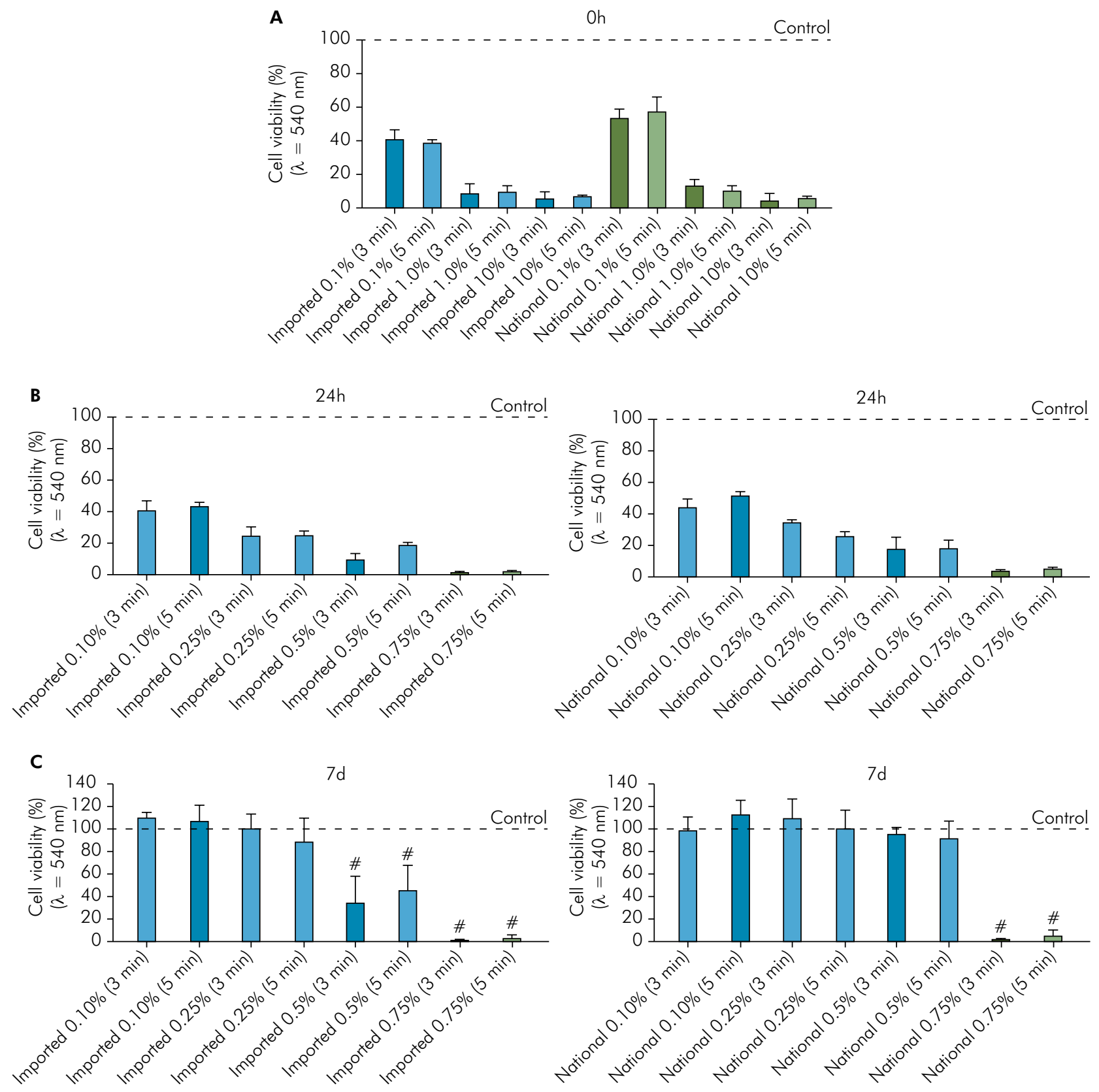

Figure 4. Evaluation of NCSs and ICSs at different concentration $s$ and the following experimental periods: immediately (A), $24 \mathrm{~h}$ (B), and 7 days (C). The time of 3 or 5 min was irrelevant for cell growth in most analyses, with the exception of $0.50 \%$ for ICS and $0.75 \%$ for both ICS and NCS at T2. \# indicates statistical difference between the cell viability evaluations after 3 and 5 min.

The untreated cells cultivated under ideal conditions showed increased viability compared with all treated groups at experimental periods of $0 \mathrm{~h}$ and $24 \mathrm{~h}$. After 7 days of cell culture at concentrations lower than $0.5 \%$ for ICS and lower than $0.75 \%$ for NCS, no statistical difference was observed for the control group.

\section{Discussion}

CS has been used predominantly for the treatment of OKC due to its capacity to fix and thus eliminate the activity of epithelial remnants. ${ }^{5,6}$ CS has also been used as an adjuvant in unicystic ameloblastoma treatment. ${ }^{171,18}$ Discrepancies regarding the adjuvant 
benefits of CS on OKC treatment have been reported previously, and although CS is not the most widely used method for OKC treatment, it is still commonly used by oral and maxillofacial surgeons. ${ }^{15}$. Commercial preparations of CS are not widely available in the market..$^{15}$ Thus, the lack of accessibility of the drug may pose an obstacle for surgeons to adopt the CS method for OKC treatment.

The high recurrence rate of OKC has prompted a search for the best treatment option. The most frequently studied therapies are marsupialization either alone or followed by enucleation, enucleation either with or without an adjunctive therapy (peripheral ostectomy, CS, and cryotherapy), and resection. 13,21,27 Enucleation of OKC with complementary site exposure to CS is considered the best conservative therapy. ${ }^{13,21,27}$ Some studies have reported the markedly reduced recurrence rates of OKCs following CS treatment. ${ }^{13,21,24}$ Despite the adjuvant benefits of CS, its caustic nature may cause irreversible damage to the surrounding soft and hard tissues..$^{28}$ Some studies have stated that it is unreasonable to use CS as adjuvant therapy for OKC treatment due to the risks to surrounding structures, such as nerves, $2,3,29$ as well as the carcinogenic effect associated with chloroform (as reported by FDA). ${ }^{23}$ Dashow et al. demonstrated a significantly decreased recurrence rate of OKCs following treatment with CS containing chloroform. ${ }^{24}$ Diaz-Belenguer et al. ${ }^{14}$ reported that the reduction in recurrence rates is not evident when CS is used as an adjuvant method. Considering this, we aimed to methodically test the effects of CS to achieve a better understanding of the cellular damage caused by the solution. Given the high recurrence rate of OKCs and evident reduction in recurrence when CS is administered, gaining a better understanding of CS is of high importance. ${ }^{13,21,24,27}$

One limitation of two-dimensional (2D) in vitro cell cultures, such as the one employed in the present study, is that the tissue architecture is not fully represented. Given that cells are grown on flat surfaces, the $2 \mathrm{D}$ cell culture method only considers a cell monolayer, which is inherently more sensitive to the effects of chemicals. Accordingly, predicting tissue response to the administration of a given substance using this method is highly challenging. Another limitation of the current study concerns the reaction of high-concentration CSs with polystyrene, which is used to manufacture the microplates used for analyses. Considering that CS concentrations above $20 \%$ damaged the microplates and impaired the measurement of absorbance, the CSs were not tested. However, the effect of CS on $\mathrm{HaCaT}$ could be compared at a maximum concentration of only $0.5 \%$, indicating that high concentrations lead to severe cytotoxicity.

The use of ICP-MS for CS characterization has not yet been reported. In the current study, ICP-MS was performed to evaluate whether the specific components of different CSs were responsible for the observed diverse cell culture responses. ICP-MS analysis showed that both the CSs contained significantly different concentrations of metals. Regarding the presence of metals in CS, one hypothesis states that they can catalyze reactions between the reagents used and alter the final composition of the solution. We cannot infer that the treatment outcomes would be different if the purity of the adjuvant solution was altered; however, we recommend that the same should be explored in future studies.

In this study, the HaCaT cell line was used. ${ }^{30}$ The CS presented significantly lower cytotoxicity at some concentrations and lengths of exposure. The study revealed that when the keratinocyte culture was treated with CS, the cell viability was severely altered by concentrations higher than $0.5 \%$ regardless of the exposure time. At low concentrations, cell viability increased with the exposure time. Lastly, there has been no consensus regarding the ideal time for CS application. ${ }^{3,11,29}$ Frerich et al. ${ }^{3}$ reported considerable damage to the neural structure after $5 \mathrm{~min}$, and there was no significant difference between the 3-and 5-minute periods. The results of the present study also demonstrated no difference between the two exposure times. Thus, it seems reasonable to suggest the application of CS for a period of no longer than $3 \mathrm{~min}$.

\section{Conclusion}

CSs are cytotoxic to human keratinocytes. However, ICS was found to be more toxic than NCS to these epithelial cells. No differences between the 3- or 5 -minute exposure times were found between the 
solutions. Further research to verify whether the differences in chemical compositions of CS can interfere with the clinical response to the drug is warranted.

\section{Acknowledgments}

This study was supported in part by grants from Fundação de Amparo à Pesquisa do Estado de Minas Gerais (FAPEMIG), Conselho Nacional de Desenvolvimento Científico e Tecnológico $(\mathrm{CNPq}$, \#310797/2019-5, \#305493/2018-3, \#435644/2018-1), and Coordenação de Aperfeiçoamento de Pessoal de Nível Superior (CAPES, Finance Code 001). L.G.A., C.C.N., and R.A.M. are research fellows of CNPq.

\section{References}

1. Zollinger R, Moritz AR. Effects of necrobiotic agent on walls of cysts experimentally produced in brain of dogs. Arch Neurol Psychiatry. 1932;28(5):1046-55. https://doi.org/10.1001/archneurpsyc.1932.02240050080005

2. Loescher AR, Robinson PP. The effect of surgical medicaments on peripheral nerve function. Br J Oral Maxillofac Surg. 1998 Oct;36(5):327-32. https://doi.org/10.1016/S0266-4356(98)90642-8

3. Frerich B, Cornelius CP, Wiethölter H. Critical time of exposure of the rabbit inferior alveolar nerve to Carnoy's solution. J Oral Maxillofac Surg. 1994 Jun;52(6):599-606. https://doi.org/10.1016/0278-2391(94)90098-1

4. Voorsmit RA, Stoelinga PJ, Haelst UJ. The management of keratocysts. J Maxillofac Surg. 1981 Nov;9(4):228-36. https://doi.org/10.1016/S0301-0503(81)80049-5

5. Voorsmit RA. The incredible keratocyst: a new approach to treatment. Dtsch Zahnarztl Z. 1985 Jun;40(6):641-4.

6. Stoelinga PJ. The treatment of odontogenic keratocysts by excision of the overlying, attached mucosa, enucleation, and treatment of the bony defect with carnoy solution. J Oral Maxillofac Surg. 2005 Nov;63(11):1662-6. https://doi.org/10.1016/j.joms.2005.08.007

7. Stoelinga PJ. Excision of the overlying, attached mucosa, in conjunction with cyst enucleation and treatment of the bony defect with carnoy solution. Oral Maxillofac Surg Clin North Am. 2003 Aug;15(3):407-14. https://doi.org/10.1016/S1042-3699(03)00033-5

8. Ohyashiki JH, Ohyashiki K, Toyama K. Analysis of DNA from cells fixed in Carnoy's solution for cytogenetic study. Cancer Genet Cytogenet. 1988 Sep;34(2):159-63. https://doi.org/10.1016/0165-4608(88)90255-5

9. Koch S, Stappenbeck N, Cornelissen CG, Flanagan TC, Mela P, Sachweh J, et al. Tissue engineering: selecting the optimal fixative for immunohistochemistry. Tissue Eng Part C Methods. 2012 Dec;18(12):976-83. https://doi.org/10.1089/ten.tec.2012.0159

10. Blanas N, Freund B, Schwartz M, Furst IM. Systematic review of the treatment and prognosis of the odontogenic keratocyst. Oral Surg Oral Med Oral Pathol Oral Radiol Endod. 2000 Nov;90(5):553-8. https://doi.org/10.1067/moe.2000.110814

11. Zhao YF, Wei JX, Wang SP. Treatment of odontogenic keratocysts: a follow-up of 255 Chinese patients. Oral Surg Oral Med Oral Pathol Oral Radiol Endod. 2002 Aug;94(2):151-6. https://doi.org/10.1067/moe.2001.125694

12. Morgan TA, Burton CC, Qian F. A retrospective review of treatment of the odontogenic keratocyst. J Oral Maxillofac Surg. 2005 May;63(5):635-9. https://doi.org/10.1016/j.joms.2004.07.026

13. Johnson NR, Batstone MD, Savage NW. Management and recurrence of keratocystic odontogenic tumor: a systematic review. Oral Surg Oral Med Oral Pathol Oral Radiol. 2013 Oct;116(4):271-6. https://doi.org/10.1016/i.0000.2011.12.028

14. Díaz-Belenguer A, Sánchez-Torres A, Gay-Escoda C. Role of Carnoy's solution in the treatment of keratocystic odontogenic tumor: A systematic review. Med Oral Patol Oral Cir Bucal. 2016 Nov;21(6):e689-95. https://doi.org/10.4317/medoral.21250

15. Ecker J, Horst RT, Koslovsky D. Current role of Carnoy's solution in treating keratocystic odontogenic tumors. J Oral Maxillofac Surg. 2016 Feb;74(2):278-82. https://doi.org/10.1016/i.joms.2015.07.018

16. Gupta A, Bansal P, Sharma R, Sharma SD. Treatment of keratocystic odontogenic tumours: a prospective study of 30 cases. J Maxillofac Oral Surg. 2016 Dec;15(4):521-7. https://doi.org/10.1007/s12663-015-0875-1

17. Haq J, Siddiqui S, McGurk M. Argument for the conservative management of mandibular ameloblastomas. Br J Oral Maxillofac Surg. 2016 Nov;54(9):1001-5. https://doi.org/10.1016/j.bjoms.2016.07.017

18. Kalaskar R, Unawane AS, Kalaskar AR, Pandilwar P. Conservative management of unicystic ameloblastoma in a young child: report of two cases. Contemp Clin Dent. 2011 Oct;2(4):359-63. https://doi.org/10.4103/0976-237X.91804

19. Kumar V. Conservative surgical approach to aggressive benign odontogenic neoplasm: a report of three cases. J Korean Assoc Oral Maxillofac Surg. 2015 Feb;41(1):37-42. https://doi.org/10.5125/jkaoms.2015.41.1.37

20. Leung YY, Lau SL, Tsoi KY, Ma HL, Ng CL. Results of the treatment of keratocystic odontogenic tumours using enucleation and treatment of the residual bony defect with Carnoy's solution. Int J Oral Maxillofac Implants. 2016 Sep;45(9):1154-8. https://doi.org/10.1016/i.ijom.2016.02.002 
Pinto Júnior AAC, Vana KSS, Abreu LG, Nascentes CC, Diniz IMA, Mesquita RA, et al.

21. Al-Moraissi EA, Dahan AA, Alwadeai MS, Oginni FO, Al-Jamali JM, Alkhutari AS, et al. What surgical treatment has the lowest recurrence rate following the management of keratocystic odontogenic tumor?: A large systematic review and meta-analysis. J

Craniomaxillofac Surg. 2017 Jan;45(1):131-44. https://doi.org/10.1016/j.jcms.2016.10.013

22. Cutler EC, Zollinger R. Sclerosing solution in the treatment of cysts and fistulae. Am J Surg. 1933;19(3):411-8. https://doi.org/10.1016/S0002-9610(33)90796-5

23. US Food and Drug Administration. FDA Compliance policy guides: section 460.200. Washington, DC: Food and Drug Administration; 1992. p. 219. 